\title{
Prophyll, calyculus, and perianth in Santalales
}

\author{
J. Kuijt ${ }^{1}$
}

\section{Key words}

biseriate corolla

calyculus

prophyll

Santalales

\begin{abstract}
The concepts of prophyll and calyculus in Santalales are reviewed, and are found to be of variable taxonomic importance in different families. The calyculus in Loranthaceae has been generally interpreted as a reduced calyx, a concept recently challenged by Wanntorp \& Ronse De Craene (2009), who concluded that it represents a fusion of prophylls. This view, as well as the accompanying biseriate corolla notion, is rejected. In Loranthaceae, prophylls associated with flowers have sometimes provided significant taxonomic features, while in Viscaceae this is true mostly in the vegetative portions of plants, especially in Arceuthobium, Dendrophthora and Phoradendron.
\end{abstract}

Published on 1 February 2013

\section{INTRODUCTION}

The Sandalwood order (Santalales) has been the subject of several significant studies in recent years. Most of these studies have dealt with the phylogenetic history of the order and its multiple components, especially the work of Nickrent et al. (2010). However, one of these contributions has instead focused on the structural elements related to flowers (Wanntorp \& Ronse De Craene 2009), and has resulted in some novel interpretations. It is the purpose of the present contribution to subject these interpretations to scrutiny.

The significant questions raised by Wanntorp \& Ronse De Craene (2009) revolve around three apparently distinct structural issues. There is, first of all, the status and occurrence of prophylls as defined below. Secondly, there is the erect rim of tissue crowning the ovary of many but not all members of the order that is known as the calyculus. It has perhaps been the most controversial morphological structure in the order, attracting various interpretations in the past. The third issue raised by Wanntorp \& Ronse De Craene is whether the corolla represents a single or a double whorl of elements. As will be seen below, these three issues are linked by various interpretations. I begin with a brief summary of the systematic occurrence of prophylls and the calyculus in Santalales.

In referring to families in Santalales, it is first necessary to deal with its recent reorganization as proposed by Nickrent et al. (2010). These authors, largely on the basis of molecular data, recognized 12 families, 4 of which are newly proposed. CrucialIy, the family Santalaceae is subdivided into 5 separate families. A detailed critique of this reorganization falls outside the scope of the present article. However, since the family descriptions are not adequately differentiated and contain important errors or undocumented statements, such as the supposed presence of the calyculus in 'Nanodeaceae', I here prefer to maintain the traditional concept of Santalaceae. The continued use of paraphyly in plant systematics has been substantially defended by Brummitt (2006), Nordal \& Stedje (2005), and especially Zander (2011). Since my taxonomic expertise is essentially limited to the mistletoes and Santalaceae, I am using other family names from the Nickrent et al. (2010) treatment, but without prejudice.

\footnotetext{
Department of Biology, University of Victoria, Victoria, BC V8W 3N5, Canada; e-mail: jkuijt@uvic.ca.
}

\section{PROPHYLLS}

Even though the term 'prophyll' is often equated to 'bracteole', it has a more precise meaning, namely one of the two often minute foliar organs that flank axillary axes in angiosperms, whether flowers, inflorescences, or vegetative ramifications. The term 'bracteole' is used inconsistently in literature; they are usually associated with flowers, while prophylls do not share that limitation. As will be seen below, prophylls are exceptionally important in Viscacean taxonomy, while bracteoles there are non-existent. In Loranthaceae the obverse is true: prophylls associated with flowers are extremely important in defining genera in the New World, but those found at the base of vegetative axes are usually ignored. Only occasionally are they prominent in that position, as in some species of Psittacanthus (Kuijt 2009); the sharply pointed prophylls in the leaf axils of Tristerix appear to be a generic feature (Kuijt 1988b, see f. 16e). Curiously, the verticillate branching pattern in Psittacanthus may occasionally indicate that prophylls do indeed exist there even though they may be scarcely recognizable; as mentioned for Arceuthobium (Viscaceae) below, even scarcely recognizable prophylls may subtend axillary ramifications.

Being very inconspicuous, it is not surprising that prophylls have not been mentioned in descriptions of the majority of Santalalean taxa. It is entirely possible that prophylls do not exist in some or all of a number of families. This applies, as far as I know, to Aptandraceae, Coulaceae, Eryrthropalaceae, Octoknemaceae, Olacaceae, Schoepfiaceae, Strombosiaceae and Ximeniaceae. It is perhaps true for many Santalaceae as well, with exceptions seen in many species of Thesium and especially in Thesidium, where each flower is flanked by a pair of large prophylls (Pilger 1935, f. 40). The same author writes: "Meist sind zwei seitliche Vorblätter vorhanden", but this is not borne out in the various generic descriptions.

\section{Loranthaceae}

The loranthaceous material used in Wanntorp \& Ronse De Craene's (2009) study consists of one species each of Passovia ('Phthirusa') and Struthanthus. Each of these genera is characterized by inflorescences bearing various numbers of paired, lateral triads. A triad consists of one central flower subtended by the primary bract (called pherophyll by Wanntorp \& Ronse 
De Craene) and a pair of flowers positioned in the axils of its prophylls. Triads may be pedunculate or essentially sessile on the inflorescence axis. It should be added that the term 'dichasium' applied by Wanntorp \& Ronse De Craene to lateral triads has also been variously circumscribed in botanical literature (Lawrence 1951, Endress 2010).

The relevant new interpretation that the authors advance, apparently based on SEM images, is that the prophylls of a loranthaceous flower fuse to form its calyculus, as is also said to be the case in Olacaceae. There is abundant evidence in the known structure especially of neotropical small-flowered Loranthaceae to the effect that this interpretation (which here will be called the 'prophyllar hypothesis') has flaws and is difficult to reconcile with the relevant literature, as detailed below.

\section{The structure of triads and dyads}

When studying the triads of Struthanthus and Passovia as well as those of other Loranthaceae, it is immediately obvious that their prophylls are physically far removed from the ovary of the median flower. It follows that there cannot have been a developmental connection between prophylls and calyculus. This is true not only for triadic small-flowered genera (all of which are neotropical), but also for Psittacanthus, Tripodanthus and others where the lateral flowers of triads (or, in Aetanthus and some Psittacanthus species, dyads) are placed on elongated pedicels. In such cases, there is no evidence that the prophylls of the triad or dyad have a developmental relationship to any of the calyculi.

\section{Monads}

Many genera, both in the New and Old World, develop inflorescences bearing single lateral flowers (monads). In many cases (Cladocolea, Tristerix, Loranthus, the upper inflorescence portions of Peristethium, etc.) flowers show no evidence of associated prophylls. In other genera, however, each flower is accompanied by a distinctive pair of prophylls; such is the case in Maracanthus (Kuijt 1976a), Oryctanthus (Kuijt 1976b), Oryctina (Kuijt (1981a), Dendropemon (Kuijt 2011a), two species of Tristerix (Kuijt 1988b) and Panamanthus (Kuijt 1991). In all these cases, a regular calyculus is formed without any developmental involvement by prophylls.

\section{Terminal flowers}

Inflorescences that are morphologically terminated by a single flower are known in a number of genera (Kuijt 1981b), for example in Loranthus, Cladocolea (Kuijt 1975), Peristethium (Kuijt 2012) and at least two Struthanthus species. Prophylls by definition are the first two phyllomes of a branch and thus do not accompany terminal flowers. In such inflorescences it would be difficult to assert that the calyculus of a lateral flower would have a different morphological origin from that of a terminal flower.

\section{Phthirusa}

Almost uniquely in Phthirusa, inflorescences are absent, the flowers being sessile in leaf axils, often in clusters. Each flower is associated with a distinctive pair of prophylls (Kuijt 2011b), which again, cannot have been developmentally involved with the formation of the ovary and its calyculus.

\section{Single pedicellate flowers}

In Ligaria and Sogerianthe, the individual flowers are stalked, no inflorescence being present, and the possibility that we are concerned with greatly reduced inflorescences remains. In any case, where prophylls are present, the calyculus is far removed from them.

\section{Viscaceae}

While in Loranthaceae prophylls appear to be of minor significance in the vegetative parts of plants, this is not so in several genera of Viscaceae. Nevertheless, here also they have not been given adequate attention. In Ginalloa and Notothixos they have not been mentioned in the relevant literature, even though the inflorescences in the former genus appear to bear them, as in the axillary 'triads' mentioned and illustrated in Barlow (1997), where they subtend secondary lateral flowers. In Korthalsella we find an unclear situation in flower-bearing regions (the concept 'inflorescence' itself is not always applicable in the genus) but, again, there is no published record of prophylls in vegetative parts of the plant (Barlow 1997). In fact, Mekel (1935) explicitly denies the presence of any prophylls in the axillary groups of flowers.

\section{Viscum}

There appears to be no previous mention of prophylls in the extensive literature on Viscum. This is surprising in what is the most famous, and most written-about of all mistletoes, V. album L. In V. album, there are regular, annual innovations of one internode each, topped by one pair of foliage leaves and a terminal inflorescence. At the very base of each innovation, there is one pair of minute, translucent, fimbriate prophylls. These structures are visible even during the winter, well before new innovations have started to elongate, and turn blackish in later years (Fig. 1a). In the axil of each prophyll, an inflorescence often develops in the next growing season. It seems safe to assume that other species of Viscum, even though most have a very different branching pattern, also have prophylls in comparable locations. Thus the position of later inflorescences can demonstrate the presence of prophylls.

\section{Dendrophthora and Phoradendron}

It is important to realize that, in contrast to the view of Eichler (1868), prophylls in Phoradendreae are distinct from any so-called basal cataphylls that may also be present. Basal cataphylls are pairs of leaf scales placed at the base of lateral ramifications in many species in both genera (Kuijt 2003), but they occur in addition to, and distal to, the prophylls. In those species that lack basal cataphylls, prophylls are nevertheless present. In a few species of Dendrophthora, the prophylls of a lateral branch may be fused to form a compound structure (Kuijt 1959). Especially in those species of Phoradendron where innovations abort terminally (dichotomous species), such prophylls usually subtend inflorescences or vegetative branches. These ramifications themselves are again provided with prophylls, etc., resulting in a highly complex but extremely regular, symmetrical grouping (Fig. 1b). The degree of prominence and the shape of prophylls, particularly in Dendrophthora, may provide important specific features taxonomically.

\section{Arceuthobium}

As far as I am aware, no mention of prophylls has appeared in the literature dealing with Arceuthobium. As in all Viscaceae, phyllotaxy is paired. Branching patterns in the genus are of two types, flabellate and verticillate (Kuijt 1970), and this has led Hawksworth \& Wiens (1970) to recognize two subgenera, subgenus Vaginata Hawksw. \& Wiens and subgenus Arceuthobium, respectively. In the flabellate pattern, younger, secondary lateral branches are added abaxially to the primary one, so that a flat, fan-like arrangement results. No prophylls are present.

The branching pattern in male $A$. americanum Nutt. ex Engelm. is essentially a replica of that of Viscum album, with one important difference: there is no sign of even minute prophylls, even though the relevant secondary branches develop in the expected positions, flanking the primary lateral branches (Fig. 1c). A second 


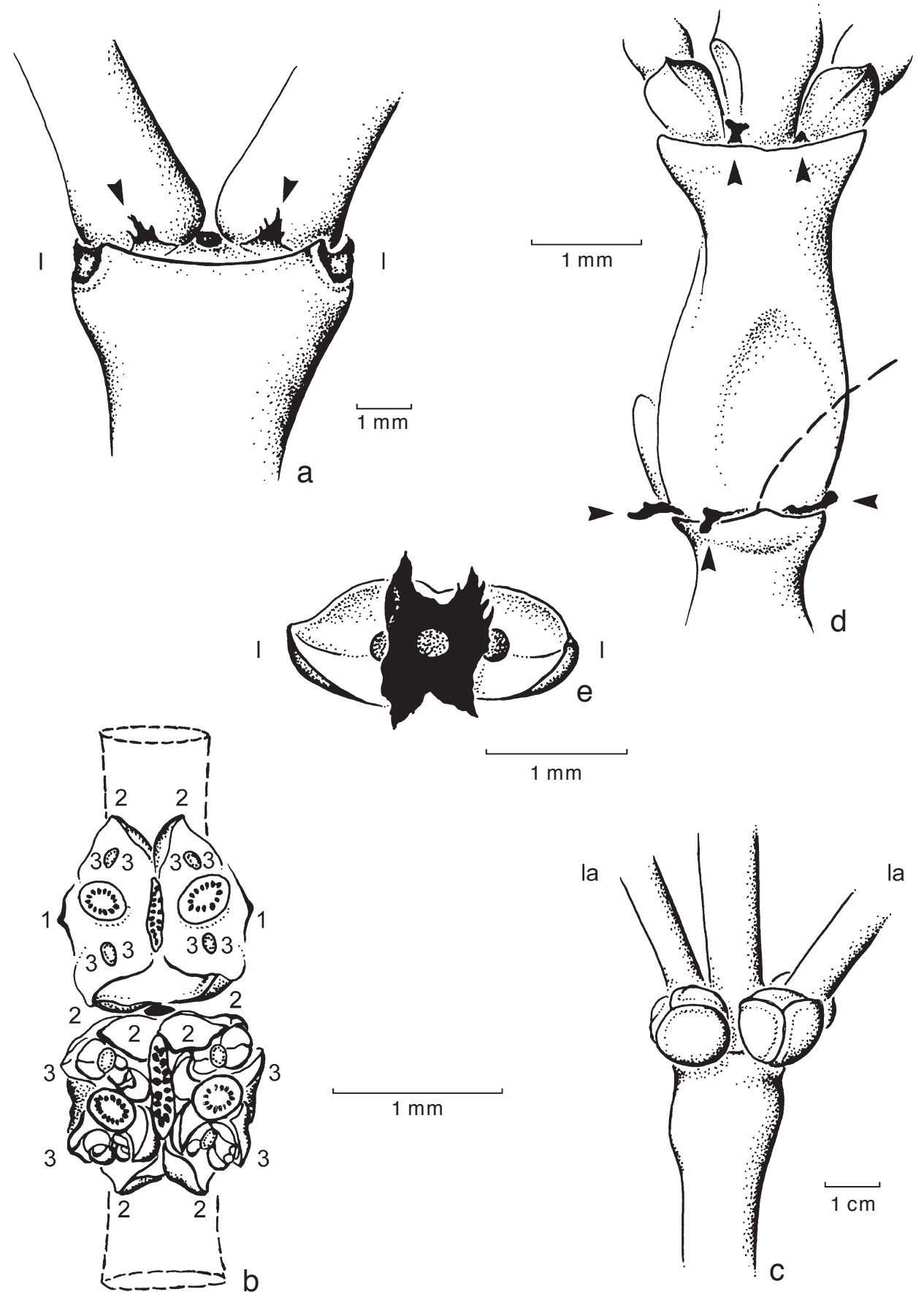

Fig. 1 Prophylls in Viscaceae. - a. Viscum album, male (Victoria, British Columbia). A year-old node, mid winter. Arrows point to the two visible prophylls. The central scar is that of last year's inflorescence, the scars of last year's leaves are indicated with 'l'. - b. Phoradendron nitens, a dichotomous species (redrawn from Kuijt 1969). The aborted apex (centre) is shown in black; foliage leaves in broken lines. Three numbered, successive generations of prophylls, flanking their inflorescence scars, are shown in the upper half of the figure, where most prophylls have been removed. - c. Arceuthobium americanum, male (Moyie, British Columbia). One type of verticillate branching, with two primary lateral branches (la) and four flower buds (one invisible) occupying prophyllar positions. No prophylls are present. - d. Arceuthobium azoricum, male (Wiens 4953, MO). View of an internode, the nearest lateral branch removed (broken line). Prophylls black (arrows). - e. Arceuthobium azoricum, male (Wiens 4953, MO). Top view of a node such as the upper one of Fig. 1d, two lateral stems and the percurrent one removed (shaded). The four prophylls (black) are fused into a single, compound structure.

difference is that female $A$. americanum has a percurrent stem system, while $V$. album is uniformly dichotomous by means of a terminal inflorescence. (The verticillate branching pattern illustrated in Hawksworth \& Wiens (1996, f. 2-1d) is incorrect).

Another species, $A$. azoricum Hawksw. \& Wiens, an endemic to the Azores, is said to be "crucial to an understanding the migrational history of the genus" (Nickrent et al. 2004). The species is also characterized by verticillate branching, as are the related $A$. oxycedri (DC.) M.Bieb. from Eurasia and Africa and $A$. juniperi-procerae Chiov. from Ethiopia and Kenya (Hawksworth \& Wiens 1976). The whorled female flowers of $A$. azoricum are said to be subtended by 'minute bracts' but, unfortunately, no details are available, and I have not been able to inspect female material. A comparison of male A. azoricum with the North American $A$. americanum leads to some intriguing facts. The main branching pattern of $A$. azoricum is identical to that of $A$. americanum; but here, each secondary lateral is subtended by a minute prophyll that emerges slightly from above the nearby leaf scale (Fig. 1d). These prophylls are black or nearly so (Fig. $1 \mathrm{~d}, \mathrm{e})$, and may be basally fused into a single, compound structure (Fig. 1e). They are almost entirely hidden by the associated leaf scales, usually extending for no more than $0.5 \mathrm{~mm}$ beyond them. The tip of a prophyll may be acute and fimbriate, or it may be blunt to laterally expanded. The existence of prophylls in this 
species almost certainly means that the $A$. americanum ancestry also had prophylls in the relevant positions, and that they have been eliminated in the past, even though its 'axillary' secondary branches do form. That leaves us with the remarkable notion of 'phantom prophylls', organs that have disappeared in the course of evolution while their morphogenetic influence has remained. Endress (2010) lists a number of comparable instances of this phenomenon in angiosperms.

\section{Eremolepidaceae}

Flowers of Eremolepidaceae lack prophylls throughout (Kuijt 1988a).

\section{Prophylls in non-mistletoe families}

While I cannot judge the data and illustrations provided by Wanntorp \& Ronse De Craene (2009) for 'Olacaceae' (Diogoa, Heisteria and Olax), there are convincing indications that in nonmistletoe families the prophyllar hypothesis must also be rejected. In those flowers where undeniable calyculi develop (sometimes after anthesis), non-articulated pedicels support them, thus making the idea of any morphogenetic contribution by even very small or unnoticed prophylls a very questionable and remote proposition.

\section{CALYCULUS}

The presence and morphological interpretation of the calyculus in Santalales has been controversial, as already indicated above. Where present, it is a rim or outgrowth from the top of the ovary, sometimes developing after anthesis to envelop the fruit partly or entirely (Kuijt 1969, Sleumer 1984). It has mostly been regarded as a reduced calyx, but Engler \& Krause (1935) considered it an outgrowth of the receptacle, and Venkata Rao (1964) introduced the idea that its origin lies in a vestigial whorl of bracts. The views of Wanntorp \& Ronse De Craene (2009) have been outlined above. Significantly, it is in the most basal genera of Loranthaceae that vasculation has been reported in the calyculus (Atkinsonia: Van Tieghem 1895, Garg 1958; Desmaria and Gaiadendron: Van Tieghem 1895; Nuytsia: Narayana 1958). Late developing calyculi such as those in Heisteria (Olacaceae) develop a profuse system of vasculation.

In Eremolepidaceae, Misodendraceae and Viscaceae the calyculus is absent. It is true that Schaeppi \& Steindl (1945) report its presence especially in the female flowers of Viscum, but this appears to refer to no more than a slight constriction below the perianth members. In some other families, the situation is not entirely clear. In Santalaceae the calyculus appears to be absent throughout, except that Nickrent et al. (2010) state it to be present in Mida and Nanodea. This is perhaps an error: at least, there is no published evidence for a calyculus in the latter genus, and the detailed illustration of the latter in Cheeseman (1914) shows nothing of the sort even though Bhatnagar (1960) does mention 5 minute lobes alternating with petals. In the same Nickrent et al. paper, Myoschilos (Santalaceae) is said to have a calyculus, but this is not documented. Also in Santalaceae, the curious foliar structures surrounding the female flower of Buckleya may or may not be comparable to a calyculus. In Erythropalum a calyculus is also absent, but in Heisteria, placed by Nickrent et al. (2010) in the same family, we find perhaps the largest calyculus in the order (Kuijt 1969, Sleumer 1984). Octoknemaceae flowers have small calyx teeth alternating with valvate petals, and Olacaceae flowers have a calyx or calyculus that becomes accrescent, tightly surrounding the fruit (Nickrent et al. 2010). Schoepfia, placed in its separate family, also has an inconspicuous calyculus (Kuijt 1969), as do Opiliaceae. What emerges from this summary is the fact that there remains a great deal of uncertainty about the distribution of a reduced calyx or calyculus outside Loranthaceae. Whether all such structures are homologous is another question.

Loranthaceous flowers always show a calyculus, with the exceptions of only the male flowers of Tupeia (Kuijt 1969) and Oryctina eubrachioides Kuijt (Kuijt 2000). Not surprisingly, it varies in size with the size of the flower. It is exceedingly small but, with the above two exceptions, always recognizable, even in the minutest flowers of the small-flowered neotropical members of the family. The largest calyculus in the family appears to be that of Aetanthus mutisii (Kunth) Engl. (Kuijt, in prep.), which is coarsely and irregularly dentate. As mentioned above, vasculated calyculi are reported in four monotypic, basal genera.

\section{BISERIATE COROLLA CONCEPT}

An additional, novel concept advanced by, or at least implied by, Wanntorp \& Ronse De Craene (2009) is the idea of a biseriate corolla in Loranthaceae, as extrapolated from the perianth of other Santalales. It is indeed true that numerous genera, nearly entirely in the New World (Kuijt 2010) demonstrate corolla dimorphism. In those taxa, each corolla consists of shorter and longer members in alternating positions (see for example, Kuijt 2009, 2011b). This dimorphism is often accompanied by an equally striking stamen dimorphism, the extremes being found in Dendropemon and two recently described species of Passovia, where sterile staminodes alternate with fertile stamens (Kuijt 2011a, b).

The evidence presented for the biseriate corolla concept consists of extrapolation and interpretation of SEM images, and is not altogether convincing. Quite aside from the fact that it is based on only two species, it must be remembered that dimorphism in the corolla and androecium is by no means universal in the Loranthaceae; in fact, it appears to be almost entirely restricted to the New World. Even there, there are species and genera that have isomorphic petals and stamens, or nearly so, as in some species of Psittacanthus (Kuijt 2009), as well as the genus Tristerix (Kuijt 1988b) and the monotypic genus Pusillanthus (Kuijt 2008). It is also difficult to appreciate how the biseriate corolla concept can apply to the numerous taxa, in both hemispheres, that have 5- or 7-merous corollas. Additionally, it is also difficult or even impossible to reconcile the concept with the existence of gamopetalous taxa in Africa (Kirkup 1998) or the campanulate flowers of the rare Mexican Cladocolea biflora Kuijt (Kuijt 1980). Since petal dimorphism exists in many mature flowers, it should come as no surprise that this fact is expressed even very early in their morphogenetic history.

\section{CONCLUSIONS}

The prophyllar hypothesis for the calyculus must be rejected in Loranthaceae, as much of the relevant published literature makes it problematic, as demonstrated above. Wanntorp \& Ronse De Craene's (2009) interpretation of their SEM images is incorrect at least in the crucial details of the calyculus. What is labelled 'calyculus' in many images instead represents the young ovary (crowned by the young calyculus), and an ovary can scarcely have been formed by the two associated prophylls. In other families of Santalales the concept remains a remote but unlikely possibility, pending on the demonstration of the existence and development of prophylls. It is recommended to adhere at this time to the traditional interpretation of the calyculus as a reduced calyx.

The biseriate corolla concept implied for Loranthaceae by the same authors must also be rejected, for separate reasons. 


\section{REFERENCES}

Barlow BA. 1997. Loranthaceae and Viscaceae. Flora Malesiana, Series I, Seed Plants 13: 209-401.

Bhatnagar SP. 1960. Morphological and embryological studies in the family Santalaceae - IV. Mida salicifolia A.Cunn. Phytomorphology 10: 198-207. Brummitt RK. 2006. Am I a bony fish? Taxon 55: 268-269.

Cheeseman TF. 1914. Illustrations of the New Zealand flora 2: 1-2, pl. 177. Eichler AW. 1868. Loranthaceae. In: Martius CFP (ed), Flora Brasiliensis 5, 2: 1-136.

Endress PK. 2010. Disentangling confusions in inflorescence morphology: patterns and diversity of reproductive shoot ramification in angiosperms. Journal of Systematics and Evolution 48: 225-239.

Engler A, Krause K. 1935. Loranthaceae. In: Engler A, Krause K (eds), Die natürlichen Pflanzenfamilien, 2nd ed, 16b: 98-203. Duncker \& Humblot, Berlin.

Garg S. 1958. Embryology of Atkinsonia ligustrina (A.Cunn. ex F.Muell.) F.Muell. Nature (London) 182: 1615-1616.

Hawksworth FG, Wiens D. 1970. New taxa and nomenclatural changes in Arceuthobium (Viscaceae). Brittonia 22: 265-269.

Hawksworth FG, Wiens D. 1976. Arceuthobium oxycedri and its segregates A. juniperi-procerae and A. azoricum. Kew Bulletin 31: 71-80.

Hawksworth FG, Wiens D. 1996. Dwarf mistletoes: biology, pathology, and systematics. United States Department of Agriculture, Forest Service, Agricultural Handbook 709.

Kirkup D. 1998. Pollination mechanisms in African Loranthaceae. In: Polhill R, Wiens D, Mistletoes of Africa: 37-60. Royal Botanical Gardens, Kew.

Kuijt J. 1959. A study of heterophylly and inflorescence structure in Dendrophthora and Phoradendron (Loranthaceae). Acta Botanica Neerlandica 8: $506-546$

Kuijt J. 1969. The biology of parasitic flowering plants. University of California Press, Berkeley \& Los Angeles.

Kuijt J. 1970. A systematic study of branching patterns in dwarf mistletoes (Arceuthobium). Memoirs of the Torrey Botanical Club 22, 4: 1-38.

Kuijt J. 1975. The genus Cladocolea (Loranthaceae). Journal of the Arnold Arboretum 56: 266-335.

Kuijt J. 1976a. Maracanthus, a new genus of Loranthaceae. Brittonia 28: 231-238

Kuijt J. 1976b. Revision of the genus Oryctanthus (Loranthaceae). Botanische Jahrbücher für Systematik 95: 478-534.

Kuijt J. 1980. Miscellaneous mistletoe notes, 1-9. Brittonia 32: 518-529.

Kuijt J. 1981a. A rejoinder on Oryctina (Loranthaceae). Plant Systematics and Evolution 137: 215-219.

Kuijt J. 1981b. Inflorescence morphology of Loranthaceae - an evolutionary synthesis. Blumea 27: 1-73.

Kuijt J. 1988a. Monograph of Eremolepidaceae. Systematic Botany Monographs 18: 1-60.

Kuijt J. 1988b. Revision of Tristerix (Loranthaceae). Systematic Botany Monographs 19: 1-61.
Kuijt J. 1991. Panamanthus, a new monotypic genus of neotropical Loranthaceae. Annals of the Missouri Botanical Garden 78: 172-176.

Kuijt J. 2000. Two new Brazilian species of Oryctina (Loranthaceae) with a revised key to the genus. Novon 10: 391-397.

Kuijt J. 2003. Monograph of Phoradendron (Viscaceae). Systematic Botany Monographs 66: 1-643.

Kuijt J. 2008. Pusillanthus (Loranthaceae), a new monotypic genus from Venezuela. Novon 18: 370-373.

Kuijt J. 2009. Monograph of Psittacanthus (Loranthaceae). Systematic Botany Monographs 86: 1-361.

Kuijt J. 2010. A note on stamen position and petal number in Loranthaceae. Blumea 55: 224-225.

Kuijt J. 2011a. Monograph of Dendropemon (Loranthaceae). Systematic Botany Monographs 92: 1-110.

Kuijt J. 2011b. Pulling the skeleton out of the closet: resurrection of Phthirusa sensu Martius and consequent revival of Passovia (Loranthaceae). Plant Diversity and Evolution 129: 159-211.

Kuijt J. 2012. Reinstatement and expansion of the genus Peristethium (Loranthaceae). Annals of the Missouri Botanical Garden 98: 542-577.

Lawrence GHM. 1951. Taxonomy of vascular plants. MacMillan, New York.

Mekel JC. 1935. Der Blütenstand und die Blüte von Korthalsella dacrydii. Blumea 1: 312-319.

Narayana R. 1958. Morphological and embryological studies in the family Loranthaceae - III. Nuytsia floribunda (Labill.) R.Br. Phytomorphology 8: 306-323.

Nickrent DL, García MA, Martín MP, Mathiasen RL. 2004. A phylogeny of all species of Arceuthobium (Viscaceae) using nuclear and chloroplast DNA sequences. American Journal of Botany 91: 125-138.

Nickrent DL, Malécot V, Vidal-Russell R, Der JP. 2010. A revised classification of Santalales. Taxon 59: 538-558.

Nordal I, Stedje B. 2005. Paraphyletic taxa should be accepted. Taxon 54 $5-6$

Pilger R. 1935. Santalaceae. In: Engler A, Prantl K (eds), Die natürlichen Pflanzenfamilien, 2nd ed, 16b: 52-91. Duncker \& Humblot, Berlin.

Schaeppi H, Steindl F. 1945. Blütenmorphologische und embryologische Untersuchungen an einigen Viscoideen. Beiheft der Vierteljahrschrift der Naturforschenden Gesellschaft Zürich 90: 1-46.

Sleumer HO. 1984. Olacaceae. Flora Neotropica 38: 1-159.

Van Tieghem P. 1895. Sur le groupement des espèces en genres dans la tribu des Gaiadendrées de la famille des Loranthacées. Bulletin du Société Botanique de France 42: 455-460.

Venkata Rao C. 1964. On the morphology of the calyculus. Journal of the Indian Botanical Society 42: 618-628.

Wanntorp L, Ronse De Craene LP. 2009. Perianth evolution in the sandalwood order Santalales. American Journal of Botany 96: 1361-1371.

Zander RH. 2011. Structuralism in phylogenetic systematics. Biological Theory 5: 383-394. 